\title{
Redox-sensitive MAPK and Notch3 regulate fibroblast differentiation and activation: a dual role of ERK1/2
}

\author{
Jun-Mei Lai ${ }^{1,2,5, *}$, Xiong Zhang ${ }^{2, *}$, Fang-Fang Liu ${ }^{1}$, Rui Yang ${ }^{1}$, Shen-Yu Li ${ }^{1}$, Lan-Bing \\ Zhu' ${ }^{2}$, Ming Zou ${ }^{2}$, Wen-Hsing Cheng ${ }^{4}$, Jian-Hong Zhu ${ }^{1,2,3}$ \\ ${ }^{1}$ Department of Preventive Medicine, Wenzhou Medical University, Wenzhou, Zhejiang 325035, China \\ ${ }^{2}$ Department of Geriatrics and Neurology, the Second Affiliated Hospital, Wenzhou Medical University, Wenzhou, Zhejiang \\ 325035, China \\ ${ }^{3}$ Key Laboratory of Watershed Science and Health of Zhejiang Province, Wenzhou Medical University, Wenzhou, Zhejiang \\ 325035, China \\ ${ }^{4}$ Department of Food Science, Nutrition and Health Promotion, Mississippi State University, Mississippi State, MS, 39762, \\ USA \\ ${ }^{5}$ Department of Rehabilitation Medicine, Zhejiang Provincial People's Hospital, Hangzhou, Zhejiang 310014, China \\ *These authors have contributed equally to the work \\ Correspondence to: Jian-Hong Zhu, email: jhzhu@wmu.edu.cn. \\ Wen-Hsing Cheng, email: wcheng@fsnhp.msstate.edu \\ Keywords: differentiation, ROS, MAPK, Notch3, lung fibrosis
}

Received: December 26, $2015 \quad$ Accepted:May 12, $2016 \quad$ Published: May 27, 2016

\section{ABSTRACT}

Myofibroblastic transformation, characterized by upregulation of a-smooth muscle actin in response to profibrotic agents such as TGF- $\beta 1$, is considered as a major event leading to fibrosis. The mechanistic basis linking myofibroblast differentiation to idiopathic pulmonary fibrosis and the disease treatment remain elusive. In this study, we studied roles of MAPK, Notch, and reactive oxygen species (ROS) during the differentiation of IMR-90 lung fibroblasts at basal level and induced by TGF- $\beta 1$. Our results demonstrated that ROS-dependent activation of p38, JNK1/ 2 and Notch 3 promoted basal and TGF- $\beta 1-$ induced differentiation and expression of extracellular matrix proteins. In stark contrast, ERK1/ 2 was suppressed by ROS and exhibited an inhibitory effect on the differentiation but showed a weak promotion on the expression of extracellular matrix proteins. TGF$\beta 1$-induced Notch 3 expression depended on p38 and JNK1/2. Interestingly, Notch 3 was also downstream of ERK1/2, suggesting a complex role of ERK1/2 in lung function. Our results suggest a novel ROS-mediated shift of dominance from the inhibitory ERK1/2 to the stimulatory p38, JNK1/ 2 and Notch 3 during the pathological progression of IPF. Thus, targeting ERK1/ 2 signaling for activation and p38, JNK1/ 2 and Notch 3 for inhibition may be of clinical potential against lung fibrosis.

\section{INTRODUCTION}

Idiopathic pulmonary fibrosis (IPF), a progressive and irreversible respiratory disease of unknown cause [1], is characterized by failure of alveolar re-epithelialization, persistence of myofibroblasts, deposition of extracellular matrix, and destruction of lung architecture [2]. Epithelial cells in IPF patients undergo chronic inflammation and release cellular mediators and cytokines, which in turn induce fibroblast migration, proliferation, and differentiation towards myofibroblasts $[3,4]$. Accumulation and persistence of myofibroblasts play central roles in lung fibrosis through pathophysiological events including the formation of fibroblast foci, excessive matrix deposition, and decreased compliance of lung parenchyma $[5,6]$.

Transforming growth factor $\beta 1$ (TGF- $\beta 1$ ), a potent cytokine, mediates signaling events during the pathogenesis of pulmonary fibrosis by the stimulation of fibroblast differentiation, extracellular matrix deposition, and tensile force in myofibroblasts $[1,7,8]$. Through interactions with Notch signaling, reactive oxygen species (ROS) and mitogen-activated protein kinases (MAPKs) including ERK, p38 and JNK, TGF- $\beta 1$ signaling regulates various cellular processes such as vascular smooth muscle differentiation and epithelial-mesenchymal transition [9-11]. It is becoming clear that the differentiation towards 
myofibroblasts is a key pathophysiological event leading to IPF [12]. Although activation of TGF- $\beta 1$ is known to be critical for differentiation into myofibroblasts [13], the underlying molecular mechanisms remain elusive. Herein, we have comprehensively investigated roles of ROS, MAPKs and Notch at basal and TGF- $\beta 1$-ativated conditions during the differentiation processes.

\section{RESULTS}

\section{p38, JNK and ERK are upstream of Notch3 signaling upon TGF- $\beta 1$-induced differentiation of IMR-90 fibroblasts}

To build a cellular model of fibroblast differentiation mimicking pulmonary fibrosis, IMR-90 fibroblasts were treated with TGF- $\beta 1(200 \mathrm{pM})$ and followed by a 48-h time course. Results from Western (Figure 1A) and immunofluorescent (Figure 1B) analyses showed time-dependent induction of alpha-smooth muscle actin ( $\alpha$-SMA), a marker of differentiated myofibroblasts, upon TGF- $\beta 1$ treatment. Analyses of MAPK and Notch activation in TGF- $\beta 1$-treated cells demonstrated time-dependent phosphorylation of $\mathrm{p} 38$ and JNK1/2, but not ERK1/2 (Figure 1C), and elevated expression of Notch3 but not Notch1 protein levels (Figure 1D). Interestingly, we observed two Notch3 bands (90 and $83 \mathrm{kDa}$, Figure 1D) whose relative abundance varied slightly with passage of cells (data not shown). They were authentic Notch3 proteins because Notch3 siRNA knockdown effectively down-regulated the expression of both bands (Figure 2C). Analyses of Notch3 downstream targets showed an up to 6-fold increase in HES1 but not HRT1 mRNA levels upon TGF- $\beta 1$ treatment (Figure 1E), suggesting that HES1 was more responsive than HRT1 to Notch3 signal in the fibroblasts.

TGF- $\beta 1$-induced phosphorylation of p38 and JNK1/2 were blocked by pre-treatment with SB203580 and SP600125, respectively, thus validating efficacy of the kinase inhibitors. Pre-treatment with SB203580 or SP600125 reversed TGF- $\beta 1$-induced expression of $\alpha$-SMA (Figure 2A and 2B). Notch3 siRNA knockdown or treatment with a Notch inhibitor DAPT suppressed TGF- $\beta 1$-induced expression of $\alpha$-SMA protein, but the former is more effective than the latter (Figure 2C). Disrupted p38, JNK1/2 and Notch3 signaling also suppressed $\alpha$-SMA protein expression at basal levels (Figure 2A-2C). We further determined the signaling cascade between $\mathrm{p} 38 / \mathrm{JNK}$ and Notch3. Pretreatment with DAPT did not affect TGF- $\beta 1$-induced phosphorylation of p38, JNK1/2 or ERK1/2 (Figure 2D). On the other hand, pre-treatment of SB203580 or SP600125 repressed TGF- $\beta 1$-induced up-regulation of Notch 3 protein expression (Figure 2E, left and middle panels), indicating that $\mathrm{p} 38$ and JNK resided upstream of Notch3 signaling in the regulation of fibroblast differentiation. Although ERK1/2 was not activated by TGF- $\beta 1$ (Figure 1C), pre-treatment with U0126 suppressed Notch3 expression in the absence and presence of TGF- $\beta 1$ (Figure 2E, right panel), suggesting that ERK was upstream of Notch3 independent of TGF- $\beta 1$. Altogether, p38, JNK and ERK act upstream of Notch3 signaling in TGF- $\beta 1$-induced fibroblast differentiation, but ERK is additionally positioned upstream of Notch3 in the absence of TGF- $\beta 1$ induction.

\section{TGF- $\beta 1$-induced fibroblast differentiation and activation of p38, JNK1/2 and Notch3 are redox- dependent}

Consistent with a previous report showing induction of ROS by TGF- $\beta 1$ [14], we found that levels of ROS in IMR-90 fibroblasts were increased upon TGF- $\beta 1$ stimulation (Figure 3A). Pre-treatment with NAC or catalase suppressed TGF- $\beta 1$-induced ROS formation (Figure 3A), $\alpha$-SMA expression (Figure 3B), Notch3 expression (Figure 3C), and phosphorylation of p38 and JNK1/2 (Figure 3D and 3E). Therefore, TGF- $\beta 1$ induces IMR-90 fibroblast differentiation through p38, JNK1/2 and Notch3 in a manner depending on ROS.

\section{ERK1/2 signaling suppresses ROS-dependent basal differentiation of IMR-90 fibroblasts}

Because $\alpha$-SMA was intrinsically expressed and could be suppressed by NAC or catalase in the absence of TGF- $\beta 1$ treatment (Figures $1 \mathrm{~A}$ and $3 \mathrm{~B}$ ), we next determined the impact of ROS and MAPK/Notch3 signaling on basal IMR-90 fibroblast differentiation. Interestingly, we observed a burst of ERK1/2 activation upon NAC or catalase treatment (Figures $3 \mathrm{~F}$ and $3 \mathrm{G}$ ), indicating that ERK1/2 signaling was suppressed by basal ROS in IMR-90 fibroblasts. In stark contrast, basal levels of phosphorylated p38 and JNK1/2 were not affected by NAC or catalase (Figures $3 \mathrm{~F}$ and $3 \mathrm{G}$ ). Basal Notch 3 level was suppressed by NAC, but not catalase (Figure 3C).

Treatment of IMR-90 fibroblasts with NAC or catalase resulted in time- and dose-dependent decreases in $\alpha$-SMA protein levels (Figures 4A and 4B), suggesting that basal ROS was required for differentiation into myofibroblasts. Subsequent analyses demonstrated that inhibition of ERK1/2 signaling by U0126 elevated $\alpha$-SMA protein levels in the presence or absence of NAC (Figure 4C), indicating an inhibitory role of ERK1/2 in basal fibroblast differentiation. Taken together, ERK1/2 signaling, but not p38/JNK-Notch3 cascade, limits differentiation of IMR-90 fibroblasts at basal levels in a ROS-dependent manner.

\section{ERK1/2 modestly inhibits TGF- $\beta 1$-induced fibroblast differentiation and collagen gel contraction}

While ERK1/2 was not activated by TGF- $\beta 1$ (Figure 1C), there was an inhibitory role of ERK $1 / 2$ in basal a-SMA expression (Figure 4C). To elaborate on 

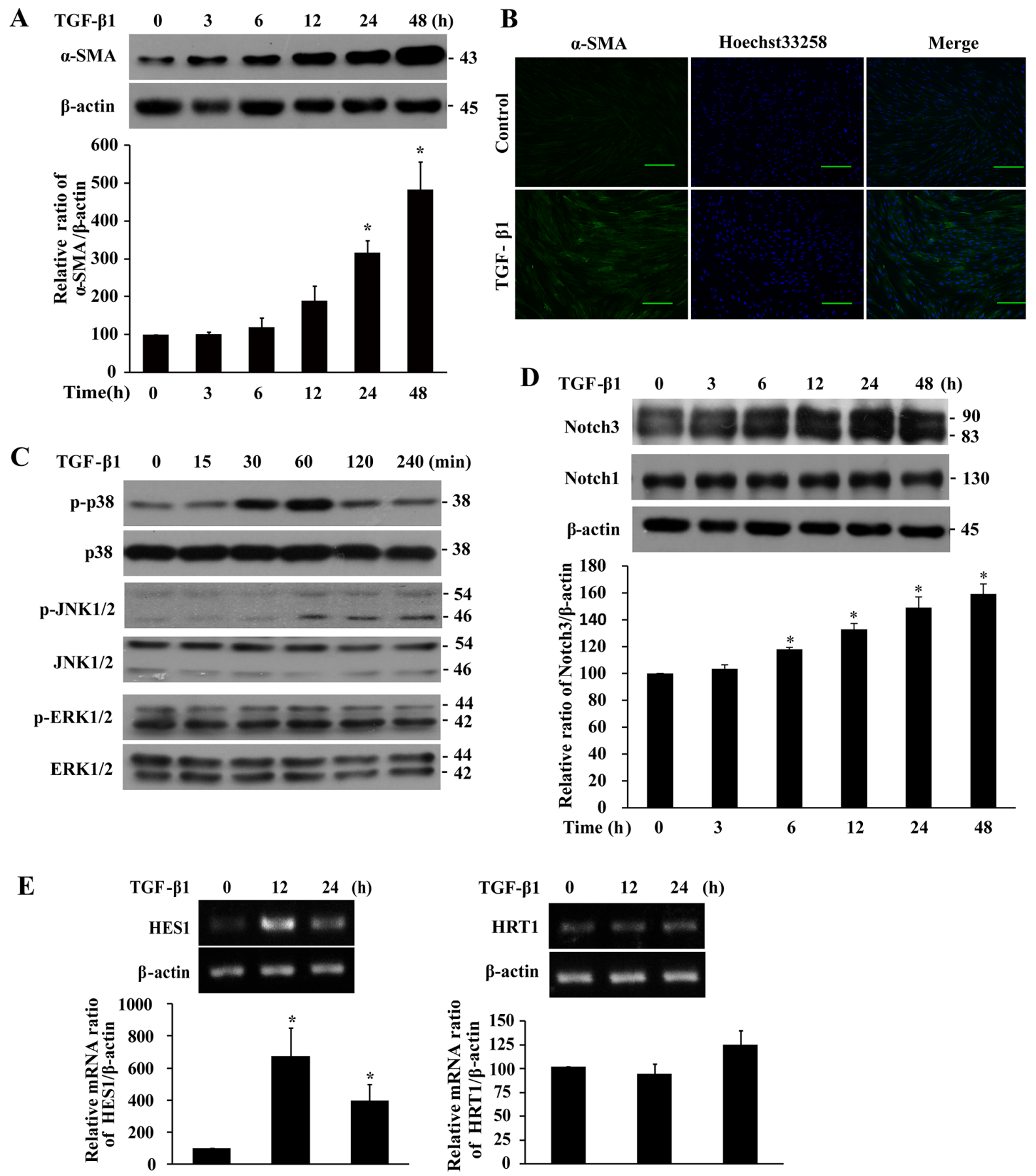

Time (h) $\quad 0 \quad 12 \quad 24$

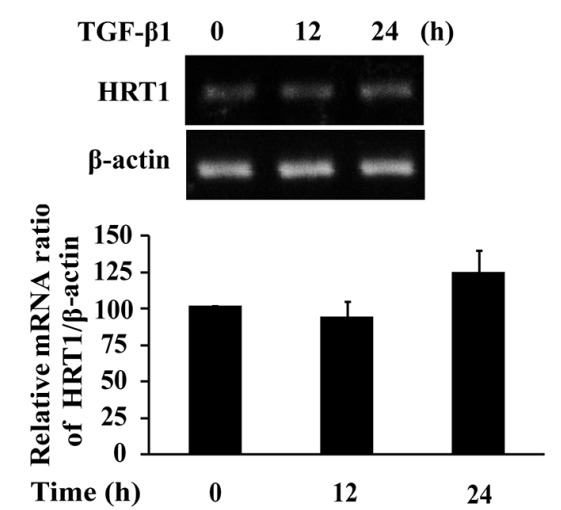

Figure 1: TGF- $\beta 1$ induces differentiation, p38 and JNK1/2 phosphorylation, and Notch3 expression in IMR-90 fibroblasts. Cells were serum-starved overnight prior to treatment with TGF- $\beta 1(200 \mathrm{pM})$ for the indicated duration. A. Western analysis of $\alpha$-SMA levels. B. Immunofluorescent analysis of $\alpha$-SMA expression. Green, $\alpha$-SMA; blue, nuclei; bar size, $100 \mu \mathrm{m}$. C. Western analysis of p38, JNK1/2 and ERK1/2 phosphorylation. D. Western analysis of Notch3 and Notch1 levels. E. RT-PCR analysis of HES1 and HRT1 mRNA levels. The bands were quantified, normalized by $\beta$-actin or the respective unphosphorylated protein, and presented relative to $0 \mathrm{~h}$ $(100 \%)$ as means $\pm \operatorname{SEM}(\mathrm{n}=3-4) .{ }^{*}, P<0.05$ vs $0 \mathrm{~h}$.

these observations, we next studied the effect of ERK1/2 on TGF- $\beta 1$-induced differentiation. Pre-treatment of IMR-90 fibroblasts with an ERK1/2 inhibitor U0126 increased a-SMA protein levels in the presence or absence of TGF- $\beta 1$ treatment as demonstrated by Western and immunofluorescent analyses (Figure 5A). The pathogenesis of lung fibrosis is closely related to the contraction characteristics of lung fibroblasts, which 
can reduce pulmonary compliance and limit stretch and expansion of the lung. Increased $\alpha$-SMA expression is known to enhance fibroblast contractile activity [15]. Results from three-dimensional collagen gel contraction assays demonstrated that TGF- $\beta 1$-induced contraction of IMR-90 fibroblasts was inhibited by NAC, SB203580, SP60012, or DAPT but modestly yet significantly $(P<$ 0.05 ) augmented by U0126 pre-treatment (Figure 5B). Thus, ERK1/2 inhibits TGF- $\beta 1$-induced differentiation of fibroblasts, which is opposite of $\mathrm{p} 38, \mathrm{JNK} 1 / 2$ and Notch3.

\section{Differential impacts on basal and TGF- $\beta 1-$ induced expression of extracellular matrix proteins by MAPKs or Notch3 in IMR-90 cells}

To further characterize pulmonary fibrosis and confirm the roles of different MAPKs and Notch3 in the pathogenesis, markers of extracellular matrix were assessed. Treatment of IMR-90 fibroblasts with TGF- $\beta 1$ resulted in elevated abundance of pro-collagen and fibronectin in the cells. Such induction of extracellular matrixes was greatly reduced when the cells were pre-treated with SP600125 or SB203580 (Figure 6B), but only modestly with U0126 (Figure 6A) or DAPT (Figure 6C). In the absence of TGF- $\beta 1$ treatment, basal pro-collagen levels were reduced by any of the MAPK and Notch inhibitors whereas levels of fibronectin were reduced by pre-treatment with SP600125, SB203580 or DAPT but not U0126. In the presence of $\mathrm{NAC}$, levels of pro-collagen and fibronectin were reduced after TGF- $\beta 1$ treatment, but only fibronectin was downregulated in the absence of TGF- $\beta 1$ (Figure 6A).

\section{Increased expression of TGF- $\beta 1, \alpha-S M A$, p-MAPKs, and Notch3 in pulmonary fibroblasts from patients with IPF and bleomycin-injured mice}

To verify clinical relevance of our findings from cultured cells, we determined TGF- $\beta 1, \alpha-S M A$, phosphorylation status of $\mathrm{p} 38, \mathrm{JNK} 1 / 2$ and ERK1/2, and Notch3 expression in IPF and normal lungs (Figure 7). Compare to sections from normal individuals, results from H\&E staining showed architectural destruction and dense fibrosis in the lungs of IPF patients. TGF- $\beta 1$ was detectable in epithelial cells, where there was evidence
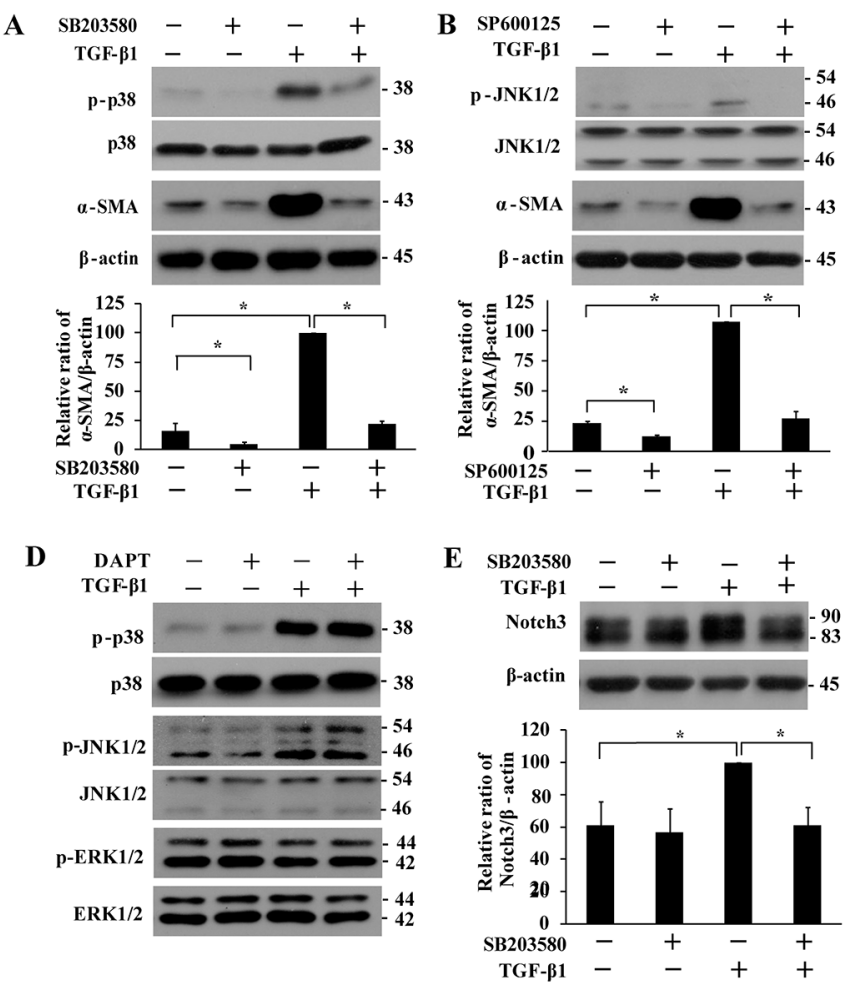
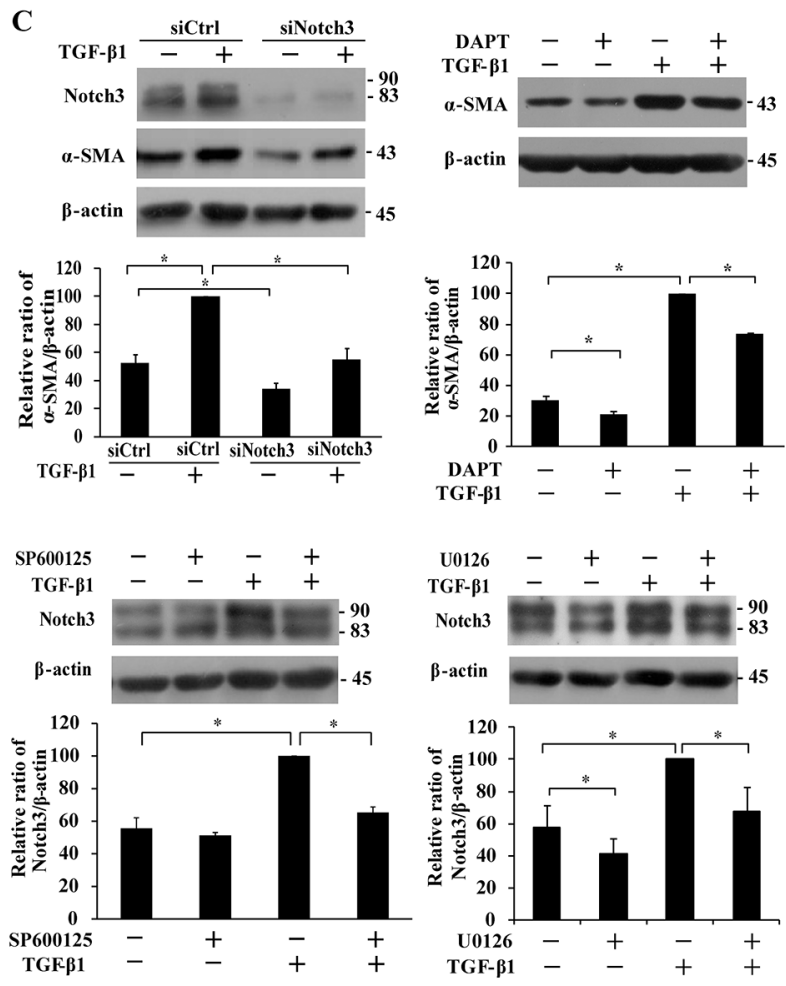

Figure 2: Analyses of the effect of p38, JNK1/2 and Notch3 inhibitions on TGF- $\beta 1$-induced $\alpha$-SMA expression and the regulation between MAPKs and Notch3 signaling in IMR-90 fibroblasts. Cells were serum-starved overnight prior to treatment with TGF- $\beta 1$ (200 pM). A-B. Effect of pretreatment with p38 inhibitor SB203580 (10 $\mu \mathrm{M}, 1 \mathrm{~h})$ and JNK inhibitor SP600125 (20 $\mu \mathrm{M}, 1 \mathrm{~h})$ on p38 and JNK1/2 phosphorylation and $\alpha$-SMA level after TGF- $\beta 1$ treatment. C. Impact of Notch3 siRNA knockdown or inhibitor DAPT (10 $\mu \mathrm{M}, 1 \mathrm{~h}$ ) on TGF- $\beta 1$-induced $\alpha$-SMA expression. Cells were transfected with a scrambled control (siCtrl) or Notch3 siRNA (siNotch3) for 24 $\mathrm{h}$ prior to treatment with TGF- $\beta 1$ for $48 \mathrm{~h}$. D. Effect of DAPT pretreatment $(10 \mu \mathrm{M}, 1 \mathrm{~h})$ on TGF- $\beta 1(1 \mathrm{~h})$-induced p38 and JNK1/2 activation, as well as ERK1/2 activity. E. Effect of p38 inhibitor SB203580 (10 $\mu \mathrm{M}, 1 \mathrm{~h})$, JNK inhibitor SP600125 (20 $\mu \mathrm{M}, 1$ h) and ERK inhibitor U0126 $(10 \mu \mathrm{M}, 1 \mathrm{~h})$ on Notch3 expression after TGF- $\beta 1$ treatment for $48 \mathrm{~h}$. The protein levels of $\alpha$-SMA and Notch 3 were quantified, normalized by $\beta$-actin and presented relative to the one treated with TGF- $\beta 1$ alone $(100 \%)$ as means \pm SEM $(\mathrm{n}=3-4)$. ${ }^{*}, P<0.05$. 
of extensive interstitial inflammation and fibrosis. While p-p38 was detected predominantly in the nuclei of fibroblasts or myofibroblasts and epithelial cells, p-JNK $1 / 2$ was observed in the cytoplasm of fibroblasts or myofibroblasts and the surrounding blood vessels. p-ERK1/2 immunoreactivity was localized in the cytoplasm of fibroblasts or myofibroblasts and vascular endothelial cells. Notch3 was found in the cytoplasm, membrane and nuclei of fibroblasts or myofibroblasts and epithelial cells. Although healthy lungs also expressed p-JNK1/2, Notch 3 and $\alpha$-SMA in the vicinity of blood vessels as shown in IPF lungs, TGF- $\beta 1$, p-p38 or p-ERK1/2 were not detected in healthy lungs.

Bleomycin is often used to induce pulmonary fibrosis although this model may not be authentic for IPF [16]. We thus determined the above proteins in the
A

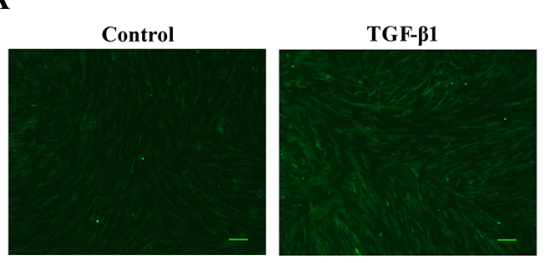

B
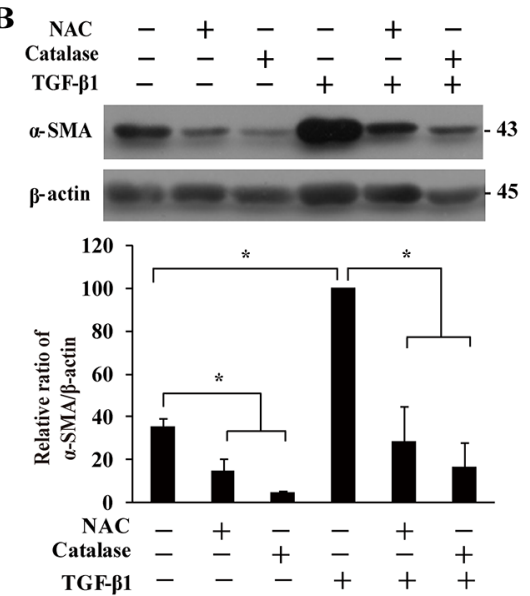

C
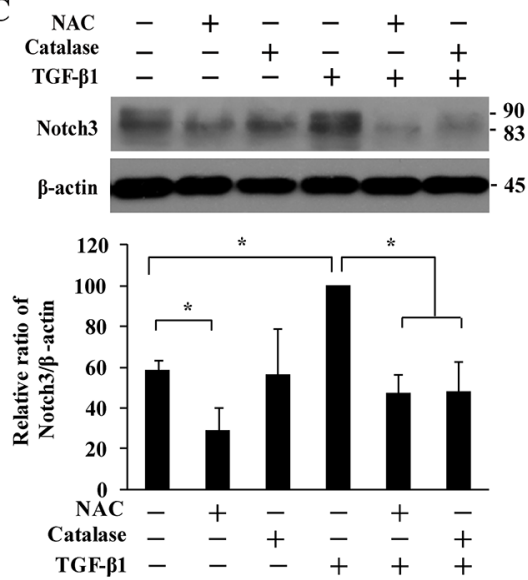

D
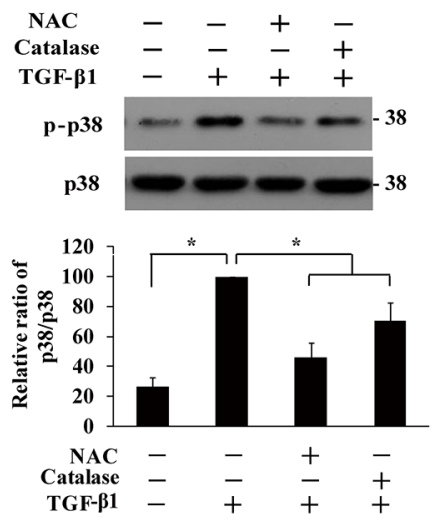

$\mathbf{E}$

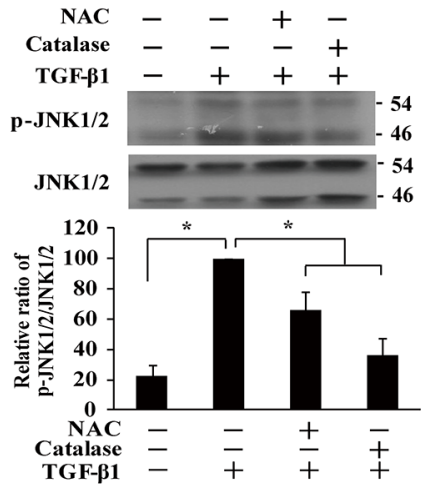

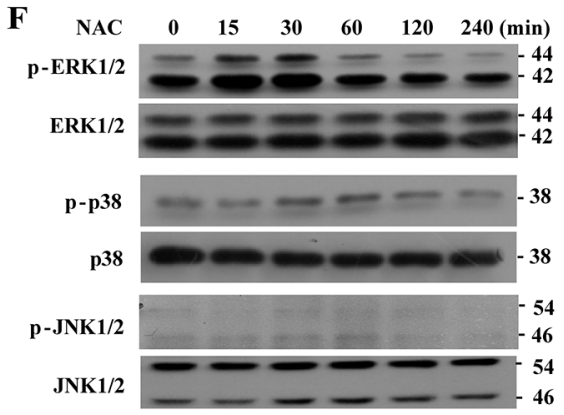

G

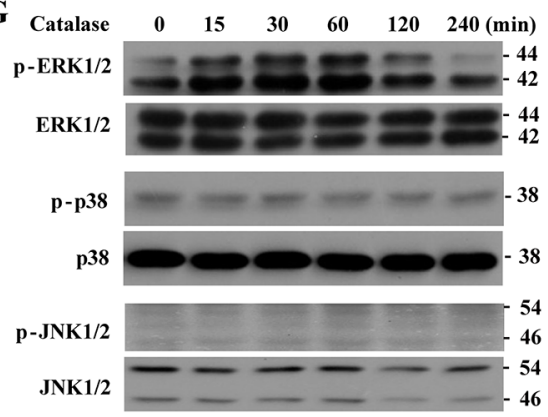

Figure 3: Effect of NAC and catalase pretreatment on basal and TGF- $\beta 1$-induced $\alpha-S M A$, MAPKs and Notch3 expression in IMR-90 fibroblasts. A. Induction of reactive oxygen species (ROS) by TGF- $\beta 1$. IMR-90 fibroblasts were treated with TGF- $\beta 1$ (200 pM, $1 \mathrm{~h})$, with or without NAC or catalase pre-treatment, followed by incubation with 2',7'-dichlorodihydrofluorescein diacetate (DCF, $10 \mu \mathrm{M}, 15 \mathrm{~min}$ ). Representative images of DCF fluorescence were shown, and ROS production was quantified and presented relative to that without any treatment as means $\pm \operatorname{SEM}(\mathrm{n}=3 ; *, P<0.05)$. Bar size, $100 \mu \mathrm{m}$. B-E. Western analyses of the effect of antioxidant pre-treatment on basal and TGF- $\beta 1$-induced expression of $\alpha$-SMA (B), Notch3 (C), phospho-p38 (D), and phospho-JNK1/2 (E). Cells were pretreated with NAC ( $4 \mathrm{mM}, 1 \mathrm{~h})$ or catalase (1000 U/L, $4 \mathrm{~h})$ prior to TGF- $\beta 1(200 \mathrm{pM})$ stimulation for $48 \mathrm{~h}$ (for $\alpha$-SMA and Notch3) or $1 \mathrm{~h}$ (for $\mathrm{p} 38$ and JNK1/2). The expression levels were quantified and normalized with their respective controls, and presented relative to that treated with TGF- $\beta 1$ alone as means \pm SEM $\left(\mathrm{n}=3-4 ;{ }^{*}, P<0.05\right)$. F-G. Expression of phosphorylated ERK1/2, p38, and JNK1/2 in IMR-90 fibroblasts treated with NAC (F, 4 mM) or catalase (G, $1000 \mathrm{U} / \mathrm{L})$ for 0-240 min. 
lungs of mice intratracheally injured by bleomycin to further study the activation status of these signaling events (Figure 8). Compare to the control sections, results from H\&E staining showed architectural destruction and dense fibrosis in the lungs at both day 7 and 28 after bleomycin treatment. However, TGF- $\beta 1$ showed a different pattern of distribution in bleomycin-induced pulmonary fibrosis compared with that in IPF patients (Figures 7 and 8A). The levels of $\alpha$-SMA, p-p38, p-ERK1/2, and Notch3, but not $\mathrm{p}-\mathrm{JNK} 1 / 2$, in the lungs were obviously induced by bleomycin treatment at both day 7 and 28 (Figure 8B, left panel). In the bleomycin-injured lungs, levels of p-p38 and Notch3, but not p-ERK1/2, were significantly increased $(P<0.05)$ at day 28 than at day 7 (Figure $8 \mathrm{~B}$, right panel).

\section{DISCUSSION}

One of the major histological patterns of usual interstitial pneumonia (UIP) is IPF, which is exemplified by the formation and persistent presence of myofibroblasts. Therapies with glucocorticoids and other immunomodulatory agents are largely ineffective for this disease [12]. It is thus thought that IPF is not significantly attributed to inflammatory responses; rather, other intracellular pathways and mediators may play a key role in the pathogenesis of UIP. While p38 and JNK are previously known to contribute to fibroblast differentiation, results from the current study present two novel findings: 1) the promotion of myofibroblast formation by a ROS-dependent and MAPK-regulated Notch3 signaling; 2) a dual role of ERK1/2 during lung fibrosis that inhibits fibroblast differentiation but promotes extracellular matrix formation.

The signaling cascades of MAPK are often involved in TGF- $\beta 1$ signaling and the associated cellular processes $[17,18]$. Our results are consistent with previous reports showing JNK and p38 activation upon TGF- $\beta 1$-stimulated myofibroblast differentiation [19-22]. Strikingly, although ERK1/2 has been shown to be activated upon TGF- $\beta 1$ stimulation in other cells [18,23], here we demonstrate that ERK1/2 activation predominantly inhibits basal differentiation of IMR-90 cells in a ROS-dependent manner. Notch signaling has been linked to fibrotic diseases $[11,24,25]$, examples of which include Notch1 promotion of differentiation in murine lung fibroblasts [24] and induction of epithelial-mesenchymal transition with increased migratory behavior in pulmonary fibrosis [11]. Interestingly, we show that Notch3, rather Notch1, is up-regulated in human IMR-90 fibroblasts upon TGF- $\beta 1$ stimulation and in IPF patients with an elevated expression of TGF- $\beta 1$. Notch3 is known to be involved in liver and kidney fibrosis [26,27], suggesting an important role of Notch3 in regulating fibrotic formation. While Notch3 is regulated by p38 in vascular smooth muscle cells [28], TGF- $\beta 1$-induced Notch3 up-regulation in fibroblasts is also downstream of JNK signaling. However, fibroblast differentiation
A
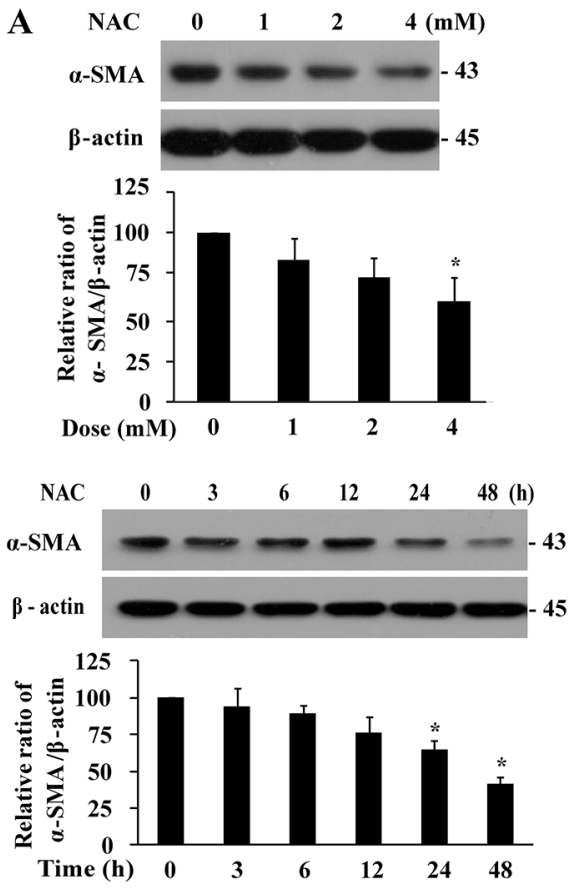

B
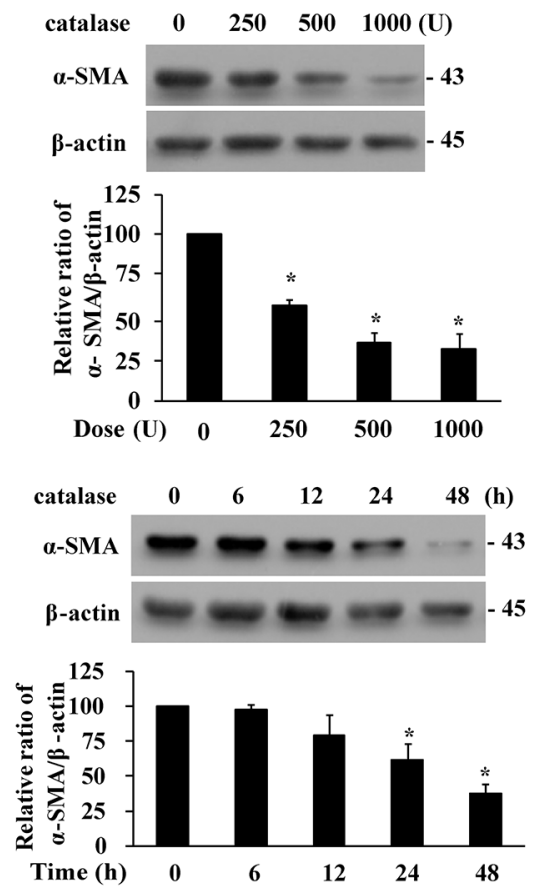

C

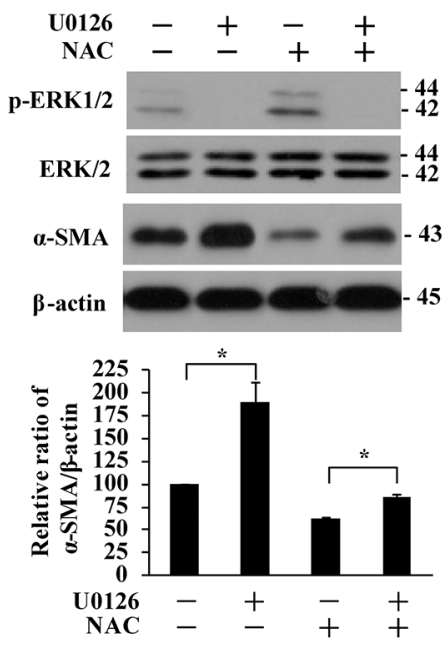

Figure 4: Basal $\alpha$-SMA expression is suppressed in the presence of antioxidant or by ERK signaling. Dose- and timedependent effect of NAC (A, $48 \mathrm{~h}$, upper panels; $4 \mathrm{mM}$, lower panels) and catalase (B, $48 \mathrm{~h}$, upper panels; $1000 \mathrm{U} / \mathrm{ml}$, lower panels) treatment on $\alpha$-SMA protein levels in IMR-90 cells. C. Effect of U0126 $(10 \mu \mathrm{M}, 1 \mathrm{~h})$ on ERK1/2 phosphorylation and $\alpha$-SMA protein levels in the presence or absence of NAC ( $4 \mathrm{mM}, 48 \mathrm{~h})$ pre-treatment. The expression levels were quantified and normalized with their respective controls, and presented relative to that without any treatment as means \pm SEM ( $\mathrm{n}=3-4$; $^{*}, P<0.05$ compared to controls). 
and expression of extracellular matrix protein by Notch3 stimulation are less significant compared to those activated by $\mathrm{p} 38$ and $\mathrm{JNK}$, implying the MAPK-mediated fibrosis only partially involves Notch3 signaling. Interestingly, the extent of gel contraction inhibition by Notch3 is similar to those by $\mathrm{p} 38$ and JNK, which may attribute to the regulation of Notch3 in mechanosensitivity [28].

Another intriguing observation is the doublet of Notch3 proteins at 83 and $90 \mathrm{kDa}$ by using an antibody against its C-terminus. While the $90 \mathrm{kDa}$ Notch3 represents the intracellular monomer after $\mathrm{S} 1$ cleavage by furin, the nature of the $83 \mathrm{kDa}$ Notch3 remains puzzling. To understand whether the $83 \mathrm{kDa}$ Notch3 is the intracellular active domain after S3 cleavage by $\gamma$-secretase, we pretreated the cells with $\gamma$-secretase inhibitor DAPT but observed no shifting of these bands (data not shown). Also, based on the size (90 amino acids or $9.7 \mathrm{kDa}$ ) between the $\mathrm{S} 1$ and $\mathrm{S} 3$ cleavage sites, the predicted molecular weight of the intracellular active domain is $80.3 \mathrm{kDa}$. Thus, the $83 \mathrm{kDa}$ Notch3 band seems to be attributed to post-translational modifications or a yet-to-be-identified proteolytic product. Although it is of future interests to elucidate the nature of these Notch3 bands observed herein in IMR-90 fibroblasts,
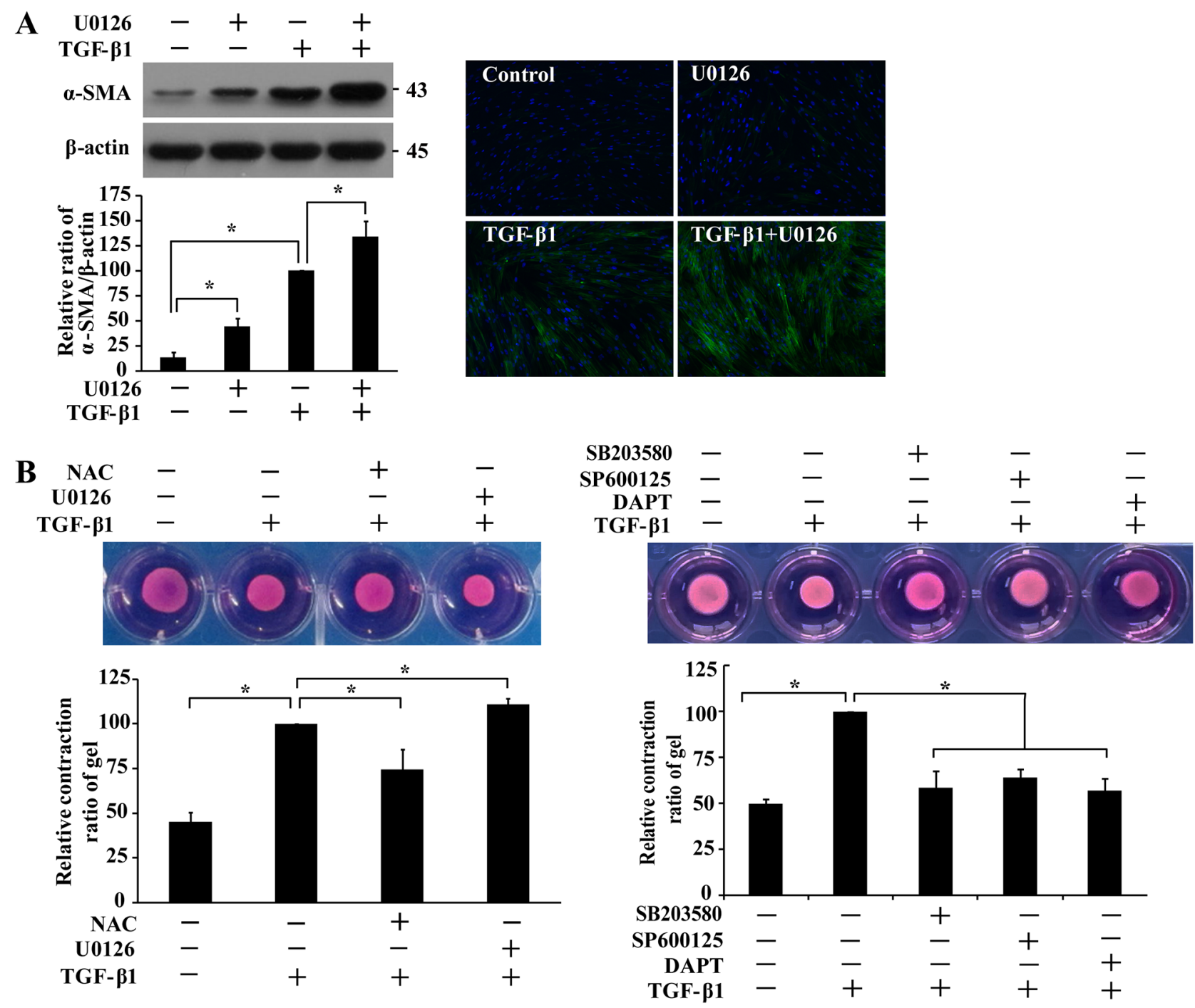

Figure 5: ERK1/2 inhibits TGF- $\beta 1$-induced $\boldsymbol{\alpha}$-SMA expression and collagen gel contraction. A. IMR-90 cells were pretreated with U0126 $(10 \mu \mathrm{M}, 1 \mathrm{~h})$ prior to TGF- $\beta 1$ treatment $(200 \mathrm{pM}, 48 \mathrm{~h})$, followed by Western and immunofluorescence analyses. $\alpha$-SMA bands were quantified and normalized with those of $\beta$-actin, and presented relative to that with only TGF- $\beta 1$ treatment as means \pm SEM $(\mathrm{n}=3-4 ; *, P<0.05)$. B. IMR-90 cells were cast into three-dimensional collagen gels and floated in medium containing NAC (4 mM), U0126 $(10 \mu \mathrm{M})$, SB203580 $(10 \mu \mathrm{M})$, SP600125 $(20 \mu \mathrm{M})$ or DAPT $(10 \mu \mathrm{M})$ for $1 \mathrm{~h}$ prior to treatment with TGF- $\beta 1(200 \mathrm{pM})$. Gel size was measured daily and representative photographs on day 3 of collagen gel contraction assay were presented. Relative contraction was calculated based on the formula, [(area at day 0 - area at day 3 )/area at day 0$] \times 100 \%$, and normalized to that treated with TGF- $\beta 1$ only. Values are means $\pm \operatorname{SEM}(\mathrm{n}=4){ }^{*}, P<0.05$. 
similar patterns of Notch3 proteins have been reported in HEK293, H460 and HeLa cells [29].

TGF- $\beta$-induced profibrotic responses are critically mediated by ROS [30-32]. Results from our current study demonstrate the involvement of ROS in TGF- $\beta 1$-induced fibroblast differentiation and TGF- $\beta 1$-induced activation of p38 and JNK and Notch3 signaling, consistent with those reported previously by using endothelial [31] and vascular smooth muscle cells [28]. A key observation reported herein is the critical role of ERK1/2 activation in the limitation of basal fibroblast differentiation under decreased oxidative stress. Such ERK1/2 function is in stark contrast to that of p38 and JNK, as they are mainly activated after TGF- $\beta 1$ induction and increased oxidative stress but not by changes in basal ROS status. Indeed, in other cell types such as primary cortical neurons and embryonic PC12 cells, NAC treatment is associated with increased expression of phosphorylated MAPK $[33,34]$. Consistent with a previous study showing inhibition of cytokine-induced activation of JNK and p38 but activation of ERK1/2 pathway by NAC [35], our data suggest that low ROS status, either at a basal level or even lower after antioxidant treatment, is in favor of ERK1/2 activation (Figures $3 \mathrm{~F}$ and $3 \mathrm{G}$ ), which, in turn, can suppress spontaneous fibrosis. Interestingly, it seems incomprehensive that ROS status at basal level is inversely associated ERK1/2 activation because TGF- $\beta 1$ stimulates
ROS production but ERK1/2 activation remains unchanged. One plausible explanation is that TGF- $\beta 1$ activates ERK1/2 via a ROS-independent pathway that offsets ROS-induced ERK1/2 inhibition by TGF- $\beta 1$. As a consequence, ERK1/2 activation remains unchanged after TGF- $\beta 1$ treatment. Of note, NAC is used for adjunct therapy to ameliorate lung fibrosis when administrated together with prednisolone and azathioprine [36]. In addition to the well-known antioxidative role of $\mathrm{NAC}$, our results suggest that the pharmacological function of NAC may act through the activation of ERK1/2 signaling to inhibit fibroblast differentiation. We also show that ERK regulates Notch3 signaling independent of TGF- $\beta 1$, suggesting an intriguing and important functional role of ERK in fibroblast differentiation. It is noteworthy that NAC per se decreases the level of Notch3 independent of ROS [37]. However, such decline seems not to affect TGF- $\beta 1$-induced MAPK activation based on the results of DAPT pre-treatments.

Such antagonistic role of ERK $1 / 2$ in pulmonary differentiation is consistent with previous studies in other cell types [38,39]. However, the inhibitory role of ERK1/2 in differentiation does not occur universally, as MEK inhibition by PD98059 has been shown to reduce lung injury and inflammation in a mouse model of pulmonary fibrosis induced by bleomycin [40]. Furthermore, in the TGF- $\alpha$-induced lung fibrosis model, ERK1/2 inhibition
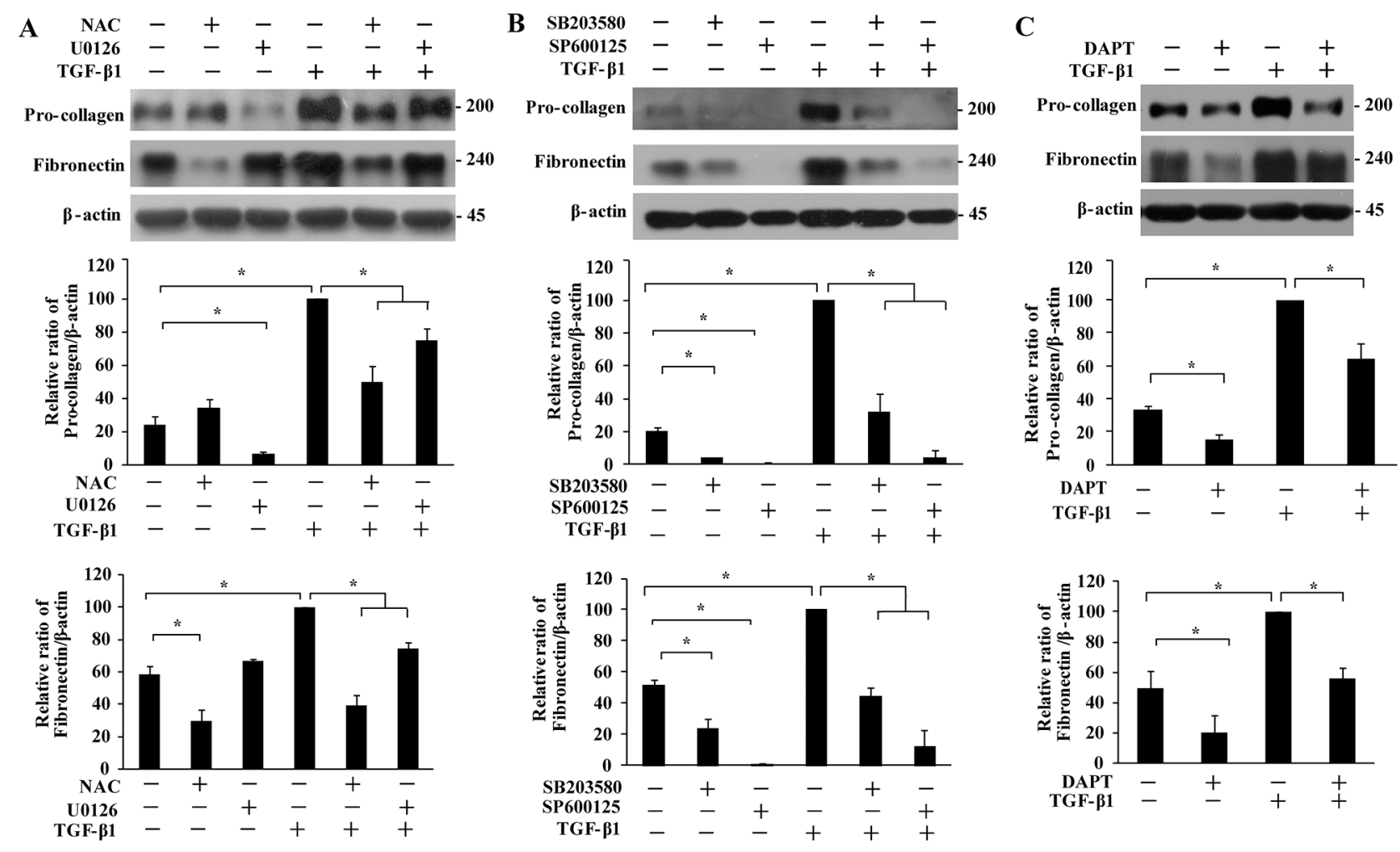

Figure 6: Effect of MAPKs and Notch3 on TGF- $\beta 1$-induced secretion of extracellular matrix proteins. IMR-90 cells were pre-treated with NAC (A, 4 mM), U0126 (A, $10 \mu \mathrm{M})$, SB203580 (B, $10 \mu \mathrm{M})$, SP600125 (B, $20 \mu \mathrm{M})$ or DAPT (C, $10 \mu \mathrm{M})$ for 1 h, followed by TGF- $\beta 1$ treatment $(200 \mathrm{pM}, 48 \mathrm{~h})$. The pro-collagen and fibronectin bands were analyzed by Western analysis, quantified, normalized to those of $\beta$-actin, and presented relative to that of TGF- $\beta 1$ treatment only as means \pm SEM $(\mathrm{n}=3) .{ }^{*}, P<0.05$. 


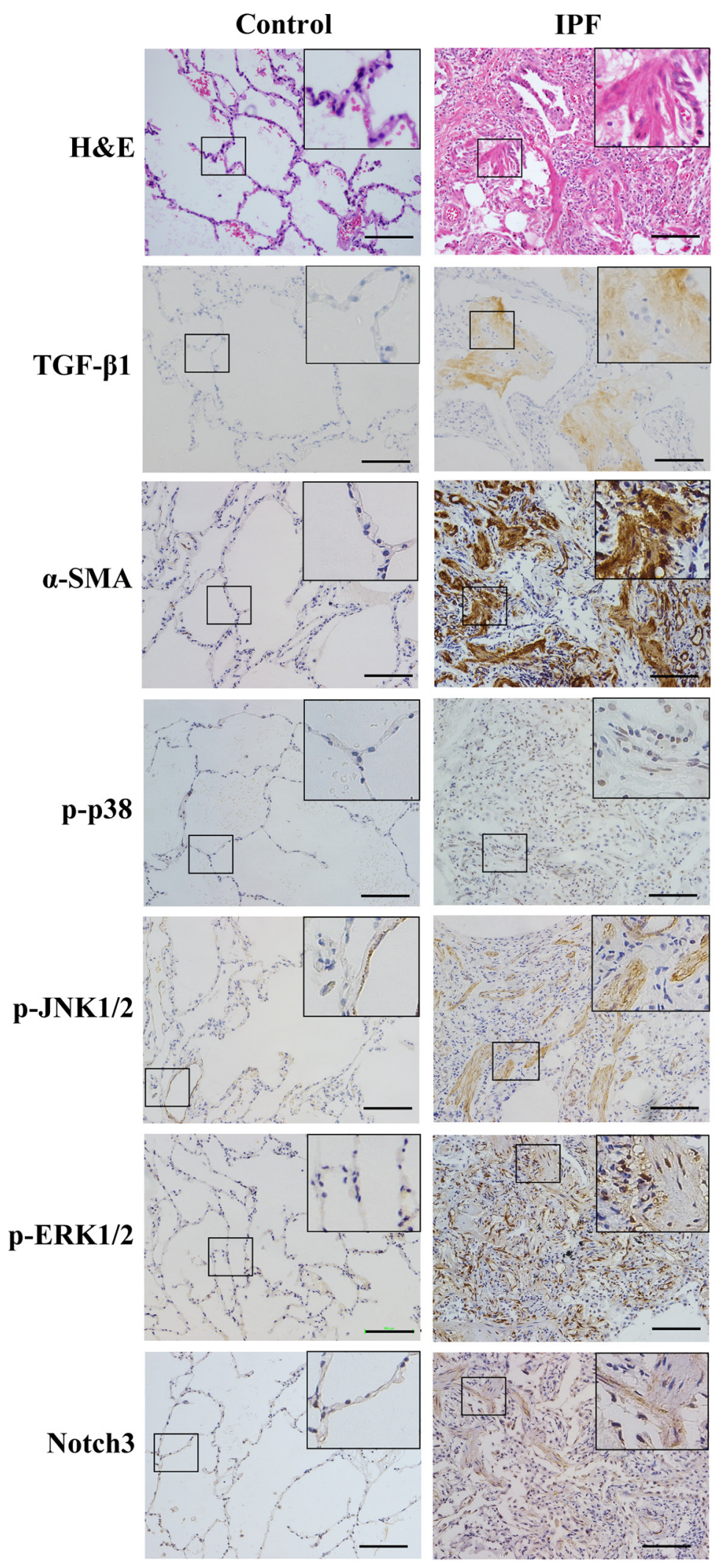

Figure 7: Representative images of immunohistochemical analyses of p38, JNK1/2, and ERK1/2 phosphorylation, $\alpha$-SMA, TGF- $\beta 1$ and Notch3 proteins and H\&E staining in paraffin-embedded lung sections from patients with idiopathic pulmonary fibrosis (IPF) and normal lung parenchyma. Bar szie, $100 \mu \mathrm{m}$. 
prevents the progression of established fibrosis [41]. To reconcile this seemingly inconsistency, we speculate that the initial secretion of pro-inflammatory cytokines and mediators following early fibrotic triggers such as epithelial-mesenchymal transition would activate ERK1/2, contributing to lung injury and inflammation. However, at later stages in the pathogenesis of IPF when fibroblast differentiation dominates, inhibition of ERK1/2 likely potentiates the progression of IPF. Indeed, unlike p38 and Notch3 showing persistent activation from day 7 to 28 in the bleomycin-injured mice, ERK1/2 signaling remains unaffected, if not inhibited, at these two time points. Although being considered by many as the fittest murine model of IPF [42], this bleomycin-induced preclinical model may not be authentic for IPF but serves as one for patients with active, instead of progressive, fibrosis [16]. Patterns of TGF- $\beta 1$ distribution in lungs of bleomycin-injured mice and IPF patients differ, since fibrosis patients are usually diagnosed only when the disease has progressed to a more advanced stage with interstitial inflammation and tissue regeneration [43]. Also, as being previously noted [44], a non-significant increase of phosphorylated JNK $1 / 2$ shows in this animal model, probably due to a differential involvement of JNK pathway in inflammatory lung injuries [44]. Furthermore, all potential anti-fibrotic compounds should be evaluated in the phase of established fibrosis rather than in the early period of bleomycin-induced inflammation for assessment of its antifibrotic properties [45]. While we are limited by the lung tissue samples of IPF patients to temporally analyze the changes of ERK1/2 activation, results from a previous study indeed suggest that ERK1/2 activation in epithelial and endothelial cells subsides accompanying the progression of fibrosis in IPF lungs [46].

Taken together, our results suggest a sophisticated participation of different MAPKs and Notch3 in maintaining and regulating fibroblast differentiation during fibrosis. As depicted in Figure 9, a basal, low ROS level sets ERK1/2 in
$\mathbf{A}$

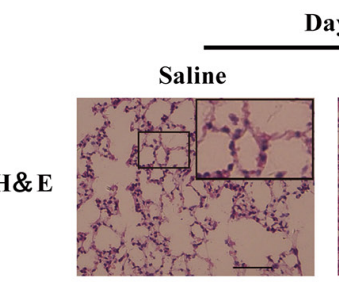

Day 7
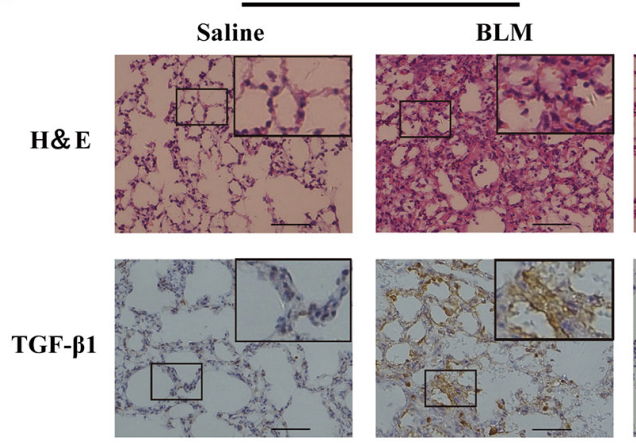

B

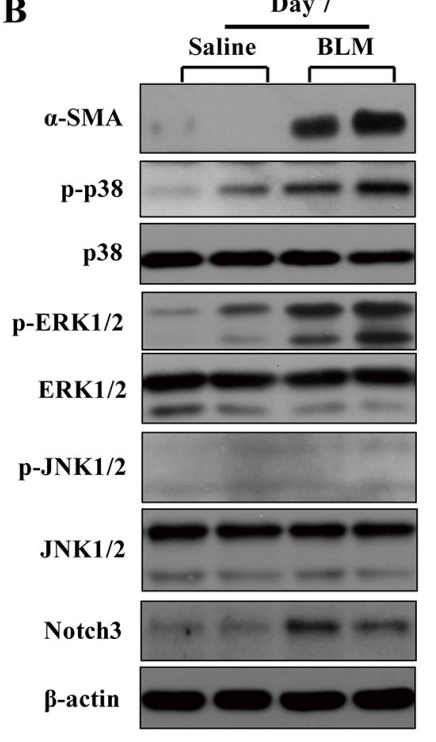

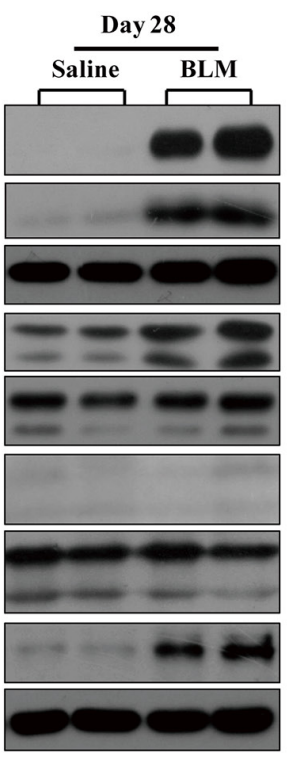
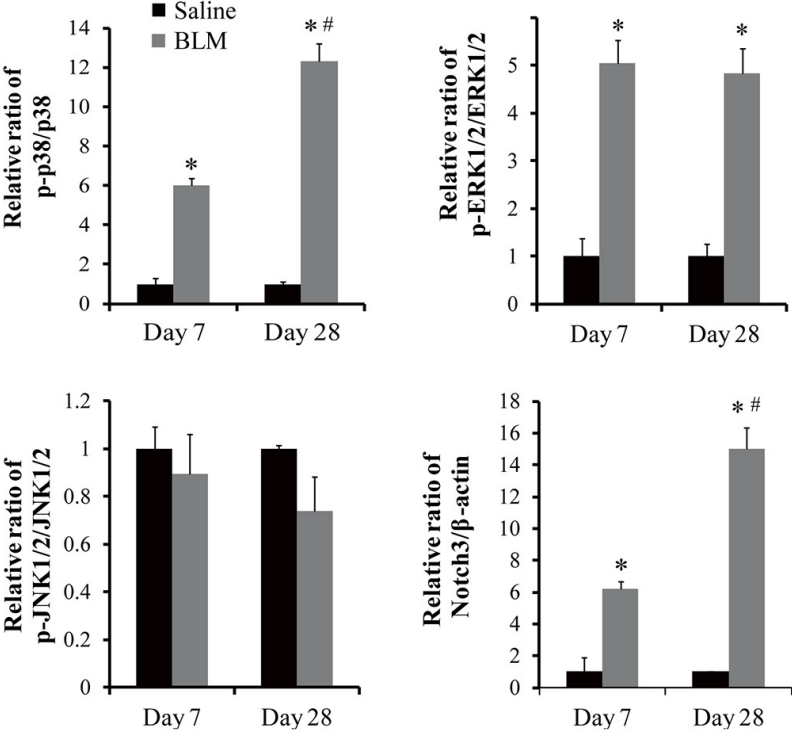

Day 28
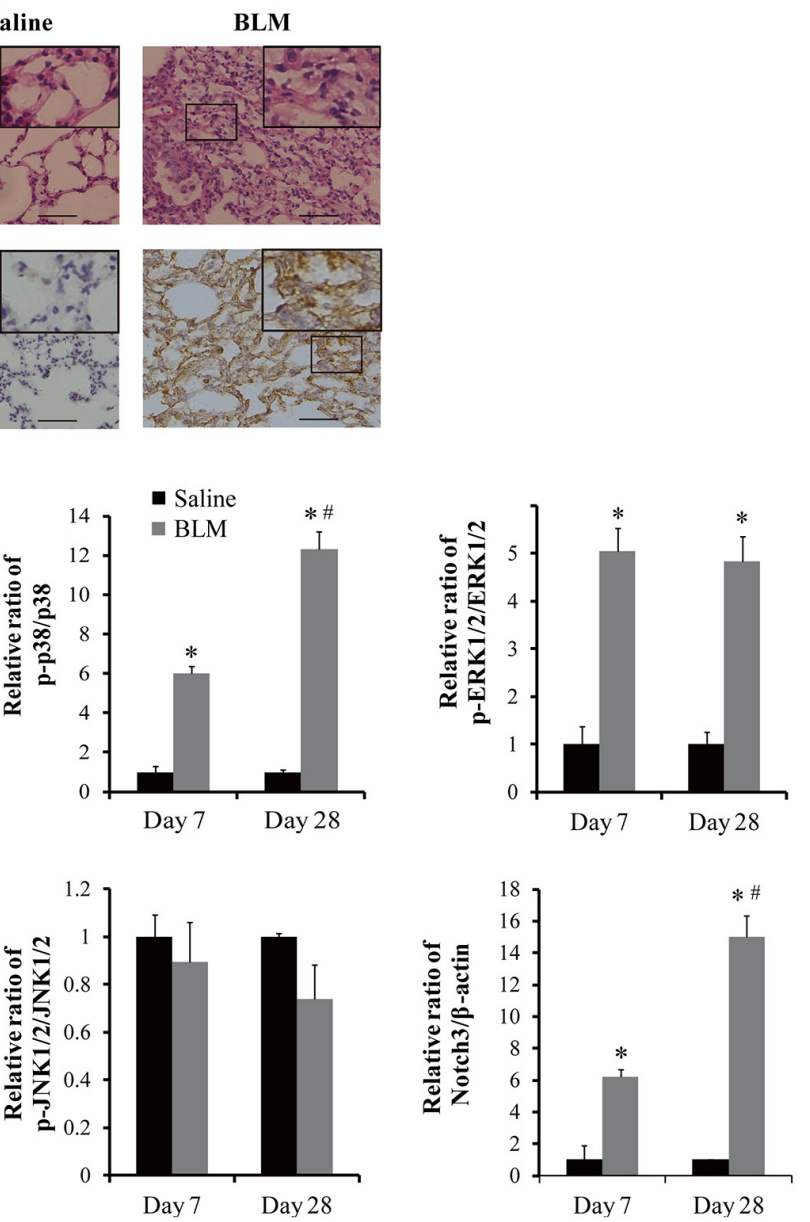

Figure 8: Analyses of phosphorylation of MAPKs, TGF- $\beta 1$ and Notch3 expression in lungs of (BLM) bleomycininjured and control mice. A. Representative images of H\&E staining and TGF- $\beta 1$ expression determined by immunohistochemistry. Bar size, $100 \mu \mathrm{m}$. B. Western blot analyses of p38, JNK1/2 and ERK1/2 phosphorylation, $\alpha$-SMA and Notch 3 expression. The protein bands were quantified, normalized with their non-phosphorylated counterparts or $\beta$-actin, and presented relative to that of saline-treated controls as means $\pm \operatorname{SEM}(\mathrm{n}=3-4){ }^{*}, P<0.05$ vs saline. $\#, P<0.05$ vs day 7. 


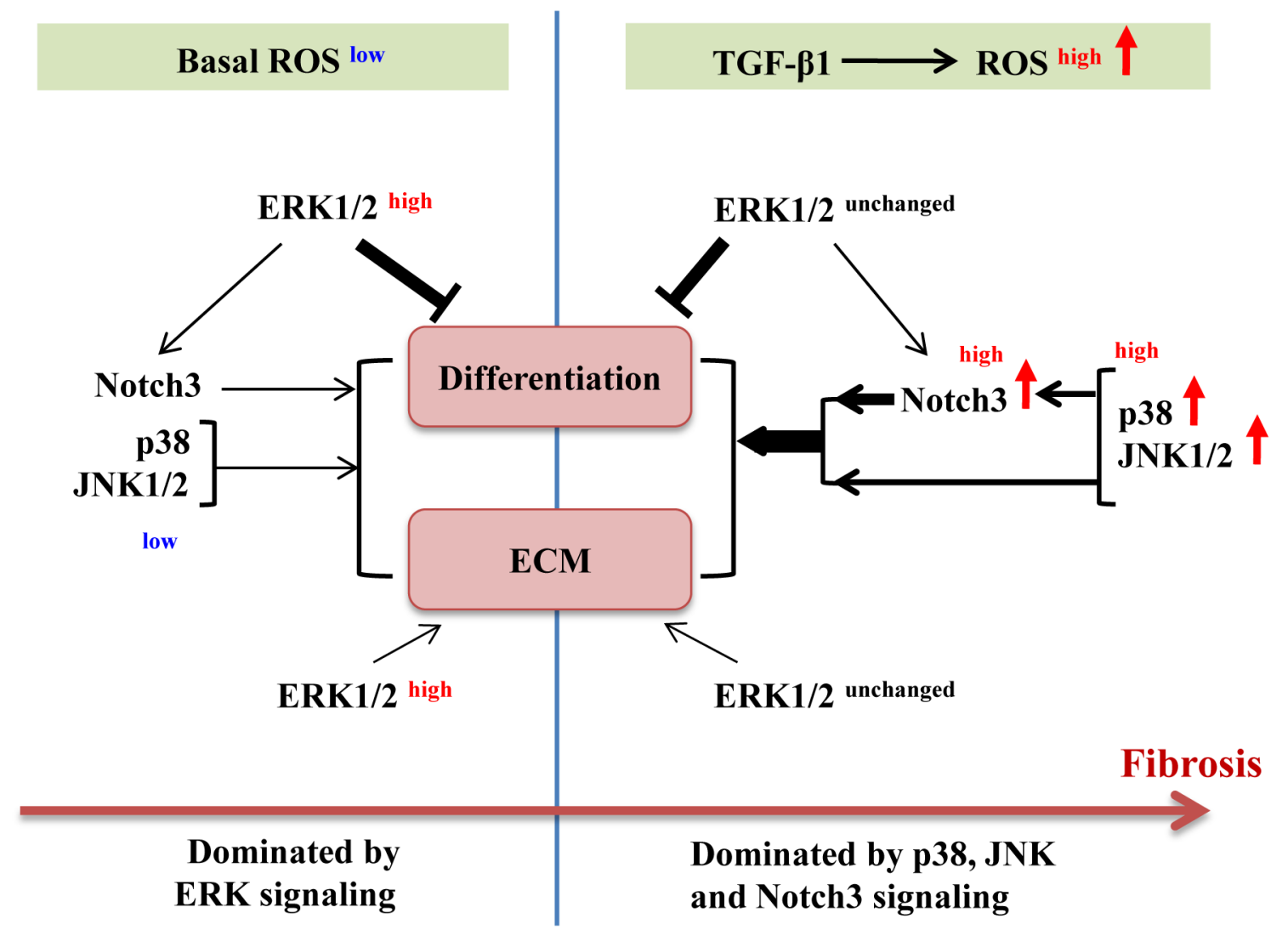

Figure 9: Schematic illustration of roles of ERK1/2, p38, JNK1/2 and Notch3 in basal and TGF- $\beta 1$-induced myofibroblast differentiation. ECM, extracellular matrix; ROS, reactive oxygen species; $\rightarrow$, lead to/activate; _, inhibit. Line thickness indicates the extent of impact. Superscripts indicate the level or activation status.

motion, which subsequently inhibits fibroblast differentiation through dominance over p38, JNK and Notch3 signals favoring differentiation. Under the circumstance of TGF- $\beta 1$ stimulation, the ROS level is dramatically elevated, resulting in enhancement of p38 and JNK1/2 activation and Notch3 expression. Consequently, the stimulatory signals including p38, JNK1/2 and Notch3 take over ERK1/2 to dictate cells towards fibrosis. To the best of our knowledge, the above evidence-based scheme is for the first time proposed toward understanding the pathogenesis of IPF, as well as to provide therapeutic potential of antioxidant and MAPK/Notch3 inhibitors in combination.

\section{MATERIALS AND METHODS}

\section{Cells and chemicals}

Human IMR-90 lung fibroblasts were purchased from American Type Culture Collection (Manassas, VA, USA) and cultured in DMEM (Invitrogen, Carlsbad, CA, USA) supplemented with 10\% fetal bovine serum (Invitrogen), penicillin $(100 \mathrm{U} / \mathrm{ml})$, and streptomycin $(100 \mu \mathrm{g} / \mathrm{ml})$ (Solarbio Science and Technology, Beijing, China) at $37^{\circ} \mathrm{C}$ in a humidified incubator with $5 \% \mathrm{CO}_{2}$. Cells at passages
7-13 were starved overnight in serum free medium before treatments. We purchased recombinant human TGF- $\beta 1$ peptide from Invitrogen (Carlsbad, CA, USA), $N$-acetyl- cysteine (NAC) and SP600125 from Beyotime (Shanghai, China), bovine liver catalase from Sigma (St. Louis, MO, USA), N-[N-(3,5-difluorophenacetyl)-_-alanyl]-Sphenylglycin $t$-butyl ester (DAPT) from Calbiochem (San Diego, CA, USA), SB203580 from Merck (San Diego, CA, USA), U0126 from Cell Signaling (Boston, MA, USA) and bleomycin from Selleck Chemicals (Houston, TX, USA). Cells were pretreated with NAC (4 mM), SP600125 (20 $\mu \mathrm{M}), \mathrm{SB} 203580(10 \mu \mathrm{M}), \mathrm{U} 0126(10 \mu \mathrm{M})$, or DAPT $(10$ $\mu \mathrm{M})$ for $1 \mathrm{~h}$, or catalase $(1000 \mathrm{U} / \mathrm{ml})$ for $4 \mathrm{~h}$ prior to TGF- $\beta 1$ (200 pM) stimulation.

\section{ROS measurement}

To assess intracellular ROS production, cells were incubated with 2', 7'-dichlorodihydrofluorescein diacetate (DCF, $10 \mu \mathrm{M}$, Beyotime) at $37^{\circ} \mathrm{C}$ for $20 \mathrm{~min}$ in serum free medium following treatments. Cells were then washed three times with PBS and immediately imaged under a fluorescence microscope with NIS-Elements D Software. In separate experiments, cells were collected following the 
PBS wash, transferred to a 96-well black-walled plate, and immediately applied to Fluoroskan Ascent FL Microplate Reader (Thermo Scientific, Waltham, MA) with excitation at $485 \mathrm{~nm}$ and emission at $538 \mathrm{~nm}$.

\section{Transfection}

Cells were transfected with siRNA sequences using Lipofectamine 2000 (Invitrogen, Carlsbad, CA, USA) according to the manufacturer's protocol. Scrambled and Notch3 siRNAs (5'-CCUGGCUACAA UGGUGAUATT-3') were purchased from GenePharma (Shanghai, China). After transfection, cells were cultured for 24 hours in complete medium prior to overnight starvation and then drug treatment.

\section{RNA isolation and mRNA analyses}

Total RNA was extracted using TRIzol reagent (Invitrogen) and reverse-transcribed to cDNA using a kit from Tiangen (Tianjin, China). HES1 and HRT1 mRNAs were amplified with the following primer pairs: HES1, 5'-GTCAACACGACACCGGATAA-3' and 5'-GAGGTGCTTCACTGTCATTTCC-3'; HRT1, 5'-TGACCGTGGATCACCTGAAA-3' and 5'-GCTGGG AAGCGTAGTTGTTG-3'; $\beta$-actin, 5'-GTGGGGCGC CCCAGGCACCA-3' and 5'-CTTCCTTAATGTCACGCA CGATTTC-3'. PCR was performed at an initial denaturation temperature at $94^{\circ} \mathrm{C}$ for $3 \mathrm{~min}$, then 35 cycles at $94^{\circ} \mathrm{C}$ for 30 sec, $48^{\circ} \mathrm{C}$ (for HES1 and HRT1) or $58^{\circ} \mathrm{C}$ (for $\beta$-actin) for 30 sec, and $72^{\circ} \mathrm{C}$ for $30 \mathrm{sec}$, and a final extension at $72^{\circ} \mathrm{C}$ for $5 \mathrm{~min}$. The PCR products were separated by a $2 \%$ agarose gel containing ethidium bromide and visualized under a gel imaging system.

\section{Western blot}

Cells were lysed in a sample buffer containing SDS (2\%) and Tris-HCl (60 mM, pH 6.8). Lysates were boiled for $5 \mathrm{~min}$ and total protein concentration was measured by using a BCA kit (Beyotime). Western analysis was performed as previously described [28] by using antibodies against Notch3 (sc-5593), $\alpha$-SMA and pro-collagen (Santa Cruz Biotechnology, Santa Cruz, CA, USA), fibronectin (Sigma), and p-JNK1/2, p-p38, p-ERK1/2, JNK1/2, p38, ERK1/2, and $\beta$-actin (Cell signaling), and a chemiluminescence detection kit (LumiGLO® Reagent and Peroxide, Cell signaling).

\section{Immunofluorescence}

Cells were fixed in cold paraformaldehyde (4\%) for $15 \mathrm{~min}$, followed by permeabilization in Triton X-100 (0.5\%) for $20 \mathrm{~min}$. After blocking with $5 \%$ bovine serum albumin (Beyotime) for $1 \mathrm{~h}$ at $4^{\circ} \mathrm{C}$, cells were sequentially incubated with anti- $\alpha-$ SMA antibody (1:200 dilution) overnight at $4^{\circ} \mathrm{C}$ and
Alexa Fluor ${ }^{\circledR}$ 488-conjugated goat anti-mouse IgG antibody (Invitrogen) for $1 \mathrm{~h}$ at $4^{\circ} \mathrm{C}$. Cells were then counterstained with Hoechst 33258 (1:2000 dilution; Beyotime) to locate the nuclei and mounted with antifade mounting media (Beyotime).

\section{Bleomycin-injured mouse model of lung fibrosis}

Male C57BL/6 mice (8-9 weeks of age, 20-23 g) were housed three to four per cage and given free access to pelleted chow diet and distilled water in an animal room maintained at constant temperature and humidity with a 12-h light-dark cycle. All animal experiments were approved by the Institutional Laboratory Animal Care and Use Committee at Wenzhou Medical University. A bleomycin-induced mouse model of lung fibrosis was generated following the protocol as described previously [47]. In brief, mice were anesthetized using $2.5 \%$ chloral hydrate and then intratracheally administered with $50 \mu \mathrm{l}$ of bleomycin $(5 \mathrm{mg} / \mathrm{kg}$ body weight) dissolved in sterile saline or only sterile saline in control mice. Mice were sacrificed at 7 or 28 days following the administration. Lungs were collected, and then fixed or homogenized in the sample buffer.

\section{Immunohistochemistry}

Histological sections were obtained from paraffinembedded lung biopsies of two controls and two IPF patients with institutional review board approval and informed written consent. Clinical criteria to identify IPF were based on the identification of a typical interstitial pneumonia pattern. Due to ethical issues, normal lung tissues from patients with lung cancer, instead of healthy individuals, were obtained and considered as the controls. In the bleomycin-induced model, mice were euthanized and perfused via the right ventricle with $10 \mathrm{ml}$ of saline. Lungs were removed, fixed overnight in formalin before being dehydrated in ethanol, and processed using standard procedures for paraffin-embedded samples. The antibody against TGF- $\beta 1$ was from Santa Cruz Biotechnology, and others were the same as described above. Immunohistochemistry was performed by using a Histostain-SP Kit (Zymed Laboratories Inc., San Francisco, CA, USA) according to the manufacturer's instructions.

\section{Collagen gel contraction assay}

Collagen gel was reconstituted using rat tail collagen type I (BD Biosciences, Bedford, MA) and cell suspension prepared in complete medium. Aliquots of the mixture $(0.5 \mathrm{ml} /$ well $)$ were then distributed to a 24 -well plate and allowed to polymerize for $30 \mathrm{~min}$ at $37^{\circ} \mathrm{C}$ before adding serum-free medium $(1 \mathrm{ml})$ to each of the wells. Following overnight starvation, the cells were pretreated as indicated and then stimulated with TGF- $\beta 1$ for 3 days. Data were 
expressed as the relative contraction ratio normalized with the area treated with TGF- $\beta 1$ only.

\section{Statistical analysis}

Data were analyzed by using Predictive Analytics Software 18.0 (PASW, version 18.0) for Windows. A oneway analysis of variance with least significant difference test was applied to determine statistical significance $(P<0.05)$.

\section{ACKNOWLEDGMENTS}

This work was supported by funding from Zhejiang Provincial Natural Science Foundation (LY14C070004, LR13H020002, and LY15H090021) and National Natural Science Foundation of China (31201065 and 81571087).

\section{CONFLICTS OF INTEREST}

The authors declare that there is no actual or potential conflict of interest.

\section{Abbreviations}

$\alpha$-SMA, $\alpha$-smooth muscle actin; DCF, 2',7'-dichlor odihydrofluorescein diacetate; IPF, idiopathic pulmonary fibrosis; MAPK, mitogen-activated protein kinase; NAC, $\mathrm{N}$-acetyl- - -cysteine; ROS, reactive oxygen species; TGF- $\beta 1$, transforming growth factor $\beta 1$; UIP, usual interstitial pneumonia

\section{REFERENCES}

1. King TE, Jr., Pardo A, Selman M. Idiopathic pulmonary fibrosis. Lancet. 2011; 378: 1949-1961.

2. White ES, Lazar MH, Thannickal VJ. Pathogenetic mechanisms in usual interstitial pneumonia/idiopathic pulmonary fibrosis. J Pathol. 2003; 201: 343-354.

3. Spagnolo P, Rossi G, Cavazza A. Pathogenesis of idiopathic pulmonary fibrosis and its clinical implications. Expert Rev Clin Immunol. 2014; 10: 1005-1017.

4. Pardo A, Selman M. Molecular mechanisms of pulmonary fibrosis. Front Biosci. 2002; 7: d1743-1761.

5. Amara N, Goven D, Prost F, Muloway R, Crestani B, Boczkowski J. NOX4/NADPH oxidase expression is increased in pulmonary fibroblasts from patients with idiopathic pulmonary fibrosis and mediates TGFbeta1induced fibroblast differentiation into myofibroblasts. Thorax. 2010; 65: 733-738.

6. Gu L, Zhu YJ, Guo ZJ, Xu XX, Xu WB. Effect of IFNgamma and dexamethasone on TGF-betal-induced human fetal lung fibroblast-myofibroblast differentiation. Acta Pharmacol Sin. 2004; 25: 1479-1488.
7. Gauldie J, Bonniaud P, Sime P, Ask K, Kolb M. TGF-beta, $\mathrm{Smad} 3$ and the process of progressive fibrosis. Biochem Soc Trans. 2007; 35: 661-664.

8. Ronnov-Jessen L, Petersen OW. Induction of alpha-smooth muscle actin by transforming growth factor-beta 1 in quiescent human breast gland fibroblasts. Implications for myofibroblast generation in breast neoplasia. Lab Invest. 1993; 68: 696-707.

9. Kennard S, Liu H, Lilly B. Transforming growth factor-beta (TGF- 1) down-regulates Notch3 in fibroblasts to promote smooth muscle gene expression. J Biol Chem. 2008; 283: 1324-1333.

10. Kim ES, Kim MS, Moon A. TGF-beta-induced upregulation of MMP-2 and MMP-9 depends on p38 MAPK, but not ERK signaling in MCF10A human breast epithelial cells. Int J Oncol. 2004; 25: 1375-1382.

11. Aoyagi-Ikeda K, Maeno T, Matsui H, Ueno M, Hara K, Aoki Y, Aoki F, Shimizu T, Doi H, Kawai-Kowase K, Iso T, Suga T, Arai M, et al. Notch induces myofibroblast differentiation of alveolar epithelial cells via transforming growth factor-\{beta\}-Smad3 pathway. Am J Respir Cell Mol Biol. 2011; 45: 136-144.

12. Gharaee-Kermani M, Hu B, Phan SH, Gyetko MR. Recent advances in molecular targets and treatment of idiopathic pulmonary fibrosis: focus on TGFbeta signaling and the myofibroblast. Curr Med Chem. 2009; 16: 1400-1417.

13. Kottmann RM, Kulkarni AA, Smolnycki KA, Lyda E, Dahanayake T, Salibi R, Honnons S, Jones C, Isern NG, $\mathrm{Hu}$ JZ, Nathan SD, Grant G, Phipps RP, et al. Lactic acid is elevated in idiopathic pulmonary fibrosis and induces myofibroblast differentiation via $\mathrm{pH}$-dependent activation of transforming growth factor-beta. Am J Respir Crit Care Med. 2012; 186: 740-751.

14. Jiang F, Liu GS, Dusting GJ, Chan EC. NADPH oxidasedependent redox signaling in TGF-beta-mediated fibrotic responses. Redox Biol. 2014; 2: 267-272.

15. Hinz B, Celetta G, Tomasek JJ, Gabbiani G, Chaponnier C. Alpha-smooth muscle actin expression upregulates fibroblast contractile activity. Mol Biol Cell. 2001; 12: 2730-2741.

16. Peng R, Sridhar S, Tyagi G, Phillips JE, Garrido R, Harris P, Burns L, Renteria L, Woods J, Chen L, Allard J, Ravindran $\mathrm{P}$, Bitter $\mathrm{H}$, et al. Bleomycin induces molecular changes directly relevant to idiopathic pulmonary fibrosis: a model for "active" disease. PLoS One. 2013; 8: e59348.

17. Das D, Holmes A, Murphy GA, Mishra K, Rosenkranz AC, Horowitz JD, Kennedy JA. TGF-beta1-Induced MAPK activation promotes collagen synthesis, nodule formation, redox stress and cellular senescence in porcine aortic valve interstitial cells. J Heart Valve Dis. 2013; 22: 621-630.

18. Huang C, Day ML, Poronnik P, Pollock CA, Chen XM. Inhibition of $\mathrm{KCa} 3.1$ suppresses TGF-beta1 induced MCP-1 expression in human proximal tubular cells through Smad3, 
p38 and ERK1/2 signaling pathways. Int J Biochem Cell Biol. 2014; 47: 1-10.

19. Meyer-Ter-Vehn T, Gebhardt S, Sebald W, Buttmann M, Grehn F, Schlunck G, Knaus P. p38 inhibitors prevent TGF-beta-induced myofibroblast transdifferentiation in human tenon fibroblasts. Invest Ophthalmol Vis Sci. 2006; 47: 1500-1509.

20. Hashimoto S, Gon Y, Takeshita I, Matsumoto K, Maruoka S, Horie T. Transforming growth Factor-betal induces phenotypic modulation of human lung fibroblasts to myofibroblast through a c-Jun-NH2-terminal kinase-dependent pathway. Am J Respir Crit Care Med. 2001; 163: 152-157.

21. Jin Lim M, Ahn J, Youn Yi J, Kim MH, Son AR, Lee SL, Lim DS, Soo Kim S, Ae Kang M, Han Y, Song JY. Induction of galectin-1 by TGF-beta1 accelerates fibrosis through enhancing nuclear retention of Smad2. Exp Cell Res. 2014; 326: 125-135.

22. Sousa AM, Liu T, Guevara O, Stevens J, Fanburg BL, Gaestel M, Toksoz D, Kayyali US. Smooth muscle alphaactin expression and myofibroblast differentiation by TGFbeta are dependent upon MK2. J Cell Biochem. 2007; 100: 1581-1592.

23. Sebe A, Leivonen SK, Fintha A, Masszi A, Rosivall L, Kahari VM, Mucsi I. Transforming growth factor-betainduced alpha-smooth muscle cell actin expression in renal proximal tubular cells is regulated by p38beta mitogenactivated protein kinase, extracellular signal-regulated protein kinase 1,2 and the Smad signalling during epithelialmyofibroblast transdifferentiation. Nephrol Dial Transplant. 2008; 23: 1537-1545.

24. Liu T, Hu B, Choi YY, Chung M, Ullenbruch M, Yu H, Lowe JB, Phan SH. Notch1 signaling in FIZZ1 induction of myofibroblast differentiation. Am J Pathol. 2009; 174: 1745-1755.

25. Kavian N, Servettaz A, Weill B, Batteux F. New insights into the mechanism of notch signalling in fibrosis. Open Rheumatol J. 2012; 6: 96-102.

26. Djudjaj S, Chatziantoniou C, Raffetseder U, Guerrot D, Dussaule JC, Boor P, Kerroch M, Hanssen L, Brandt S, Dittrich A, Ostendorf T, Floege J, Zhu C, et al. Notch-3 receptor activation drives inflammation and fibrosis following tubulointerstitial kidney injury. J Pathol. 2012; 228: 286-299.

27. Chen Y, Zheng S, Qi D, Zheng S, Guo J, Zhang S, Weng Z. Inhibition of Notch signaling by a gamma-secretase inhibitor attenuates hepatic fibrosis in rats. PLoS One. 2012; 7: e46512.

28. Zhu JH, Chen CL, Flavahan S, Harr J, Su B, Flavahan NA. Cyclic stretch stimulates vascular smooth muscle cell alignment by redox-dependent activation of Notch3. Am J Physiol Heart Circ Physiol. 2011; 300: H1770-1780.

29. Jia L, Yu G, Zhang Y, Wang MM. Lysosome-dependent degradation of Notch3. Int J Biochem Cell Biol. 2009; 41: 2594-2598.
30. Samarakoon R, Overstreet JM, Higgins PJ. TGF-beta signaling in tissue fibrosis: redox controls, target genes and therapeutic opportunities. Cell Signal. 2013; 25: 264-268.

31. Yan F, Wang Y, Wu X, Peshavariya HM, Dusting GJ, Zhang M, Jiang F. Nox4 and redox signaling mediate TGF-betainduced endothelial cell apoptosis and phenotypic switch. Cell Death Dis. 2014; 5: e1010.

32. Bondi CD, Manickam N, Lee DY, Block K, Gorin Y, Abboud HE, Barnes JL. NAD(P)H oxidase mediates TGFbeta1-induced activation of kidney myofibroblasts. J Am Soc Nephrol. 2010; 21: 93-102.

33. Lin CH, Kuo SC, Huang LJ, Gean PW. Neuroprotective effect of $\mathrm{N}$-acetylcysteine on neuronal apoptosis induced by a synthetic gingerdione compound: involvement of ERK and p38 phosphorylation. J Neurosci Res. 2006; 84: 1485-1494.

34. Yan CY, Greene LA. Prevention of PC12 cell death by $\mathrm{N}$-acetylcysteine requires activation of the Ras pathway. $\mathrm{J}$ Neurosci. 1998; 18: 4042-4049.

35. Zafarullah M, Li WQ, Sylvester J, Ahmad M. Molecular mechanisms of $\mathrm{N}$-acetylcysteine actions. Cell Mol Life Sci. 2003; 60: 6-20.

36. Gogali A, Wells AU. New pharmacological strategies for the treatment of pulmonary fibrosis. Ther Adv Respir Dis. 2010; 4: 353-366.

37. Zhang X, Wang YN, Zhu JJ, Liu XX, You H, Gong MY, Zou M, Cheng WH, Zhu JH. N-acetylcysteine negatively regulates Notch3 and its malignant signaling. Oncotarget. 2016; 7: 30855-30866. doi: 10.18632/oncotarget.8806.

38. Kawai-Kowase K, Sato H, Oyama Y, Kanai H, Sato M, Doi H, Kurabayashi M. Basic fibroblast growth factor antagonizes transforming growth factor-betal-induced smooth muscle gene expression through extracellular signal-regulated kinase 1/2 signaling pathway activation. Arterioscler Thromb Vasc Biol. 2004; 24: 1384-1390.

39. Liu X, Hubchak SC, Browne JA, Schnaper HW. Epidermal growth factor inhibits transforming growth factor-betainduced fibrogenic differentiation marker expression through ERK activation. Cell Signal. 2014; 26: 2276-2283.

40. Galuppo M, Esposito E, Mazzon E, Di Paola R, Paterniti I, Impellizzeri D, Cuzzocrea S. MEK inhibition suppresses the development of lung fibrosis in the bleomycin model. Naunyn Schmiedebergs Arch Pharmacol. 2011; 384: 21-37.

41. Madala SK, Schmidt S, Davidson C, Ikegami M, Wert S, Hardie WD. MEK-ERK pathway modulation ameliorates pulmonary fibrosis associated with epidermal growth factor receptor activation. Am J Respir Cell Mol Biol. 2012; 46: 380-388.

42. Moore BB, Hogaboam CM. Murine models of pulmonary fibrosis. Am J Physiol Lung Cell Mol Physiol. 2008; 294: L152-160.

43. Khalil N, O'Connor RN, Unruh HW, Warren PW, Flanders $\mathrm{KC}$, Kemp A, Bereznay OH, Greenberg AH. Increased production and immunohistochemical localization of 
transforming growth factor-beta in idiopathic pulmonary fibrosis. Am J Respir Cell Mol Biol. 1991; 5: 155-162.

44. Li LF, Liao SK, Huang CC, Hung MJ, Quinn DA. Serine/ threonine kinase-protein kinase $\mathrm{B}$ and extracellular signalregulated kinase regulate ventilator-induced pulmonary fibrosis after bleomycin-induced acute lung injury: a prospective, controlled animal experiment. Crit Care. 2008; 12: R103.

45. Moeller A, Ask K, Warburton D, Gauldie J, Kolb M. The bleomycin animal model: a useful tool to investigate treatment options for idiopathic pulmonary fibrosis? Int $\mathbf{J}$ Biochem Cell Biol. 2008; 40: 362-382.

46. Yoshida K, Kuwano K, Hagimoto N, Watanabe K, Matsuba T, Fujita M, Inoshima I, Hara N. MAP kinase activation and apoptosis in lung tissues from patients with idiopathic pulmonary fibrosis. J Pathol. 2002; 198: 388-396.

47. Cai Y, Kimura S. Noninvasive intratracheal intubation to study the pathology and physiology of mouse lung. J Vis Exp. 2013: e50601. 